\title{
Multivariate Analysis of Genetic Variation in Rapeseed (Brassica Napus L.)
}

\section{Elora Parvin ${ }^{1 × ~(D) ~}$ \\ Firoz Mahmud ${ }^{2}$ \\ Md. Shahidur Rashid Bhuiyan ${ }^{3}$ \\ Md. Maksudul Haque ${ }^{4}$}

'Scientific Officer, Bangladesh Institute of Research and Training on Applied Nutrition (BIRTAN), Dhaka, Bangladesh

Email:elora@birtan.gov.bd

${ }^{2,2}$ Professor, Department of Genetics and Plant Breeding, Sher-e-Bangla Agricultural University, Dhaka-1207, Bangladesh

'Email:fmahmudos@gmial.com Tel:01552432589

'Email:ipbscfc2009@gmail.com Tel:01552467945

'Senior Scientific Officer, Bangladesh Institute of Research and Training on Applied Nutrition (BIRTAN), Dhaka, Bangladesh

'Email:maksudulhq@gmail.com

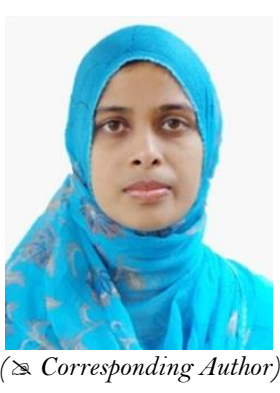

Corresponding Author

\section{Abstract}

Designing breeding programs for rapeseed (Brassica napus L.) cultivars with developed seed and oil yields needs information about the genetic variability of characters. In this study, 40 rapeseed genotypes were evaluated for genetic variation and relationships between 12 agro-morphological characters. Brassica species represent a broad range of crops. This redirects the high degree of genetic diversity and allied phenotypic plasticity. Significant differences among the clusters were observed. The first two components with Eigen value were greater than unity contributed a total of $42.77 \%$ variation to the divergence. The genotypes were grouped into five clusters. Cluster $\mathrm{V}$ contained the maximum number of genotypes (11) and cluster III contained the lowest (4). The highest inter-cluster distance was found between cluster II and cluster V and the lowest between cluster II and cluster IV. The highest intra-cluster distance was noticed for cluster I and the lowest for cluster V. Considering diversity pattern and other agronomic performance lines Nap0837, Nap-0733-1, Nap-2066, Nap-9901, Nap-108 and BARI-8 could be considered apposite parents. This information is suitable for hybrid breeding and encouraging breeders to exchange their germplasm as to enlarge the genetic diversity of breeding accessions.

Keywords: Multivariate analysis, Genetic variation, Rapeseed

Citation | Elora Parvin; Firoz Mahmud; Md. Shahidur Rashid Bhuiyan; Md. Maksudul Haque (2019). Multivariate Analysis of Genetic Variation in Rapeseed (Brassica Napus L.). Agriculture and Food Sciences Research, 6(1): 1-8.

History:

Received: 18 October 2018

Revised: 23 November 201

Accepted: 4 January 2019

Published: 2 February 2019

Licensed: This work is licensed under a Creative Commons

Attribution 3.0 License $(\mathrm{cc})$ EY

Publisher: Asian Online Journal Publishing Group
Contribution/Acknowledgement: All authors contributed to the conception and design of the study.

Funding: This study received no specific financial support.

Competing Interests: The authors declare that they have no conflict of interests.

Transparency: The authors confirm that the manuscript is an honest, accurate, and transparent account of the study was reported; that no vital features of the study have been omitted; and that any discrepancies from the study as planned have been explained.

Ethical: This study follows all ethical practices during writing.

\section{Contents}

1. Introduction

2. Materials and Methods 


\section{Introduction}

Rapeseed (Brassica napus L., 2n=38) is an important oil seed crop belonging to the family Cruciferae. The seeds of mustard and rapeseed contain $42 \%$ oil and $25 \%$ protein. Oilseed rape (Brassica napus L.) is third most important oil crop in the world. Today oilseed rape (B. napus ssp. napus) is the most important source of vegetable oil in Europe and the second most important oilseed crop in the world after soybean. However, its limited geographic range and intensive breeding has led to a fairly thin genetic basis in present breeding material. The gene pool of elite oilseed rape breeding material has been more eroded by an emphasis on specific oil and seed quality characters. As a consequence, genetic variability in this vital crop is restricted with regard to several characters of importance for breeding purposes. Oil and fat are not only the basis of energy but they also contain fat-soluble vitamins A, D, $\mathrm{E}$ and K. The oil cake holds proteins of high biological value and applicable quantities of calcium and phosphorus and is used as a very good animal feed as well as fertilizer for many crops. Rapeseed laterally with mustard is currently ranked as the world's third vital edible oil crop in terms of area and production after soybean and cotton. Major producing areas include Canada, China, northern Europe, and the Indian sub-continent. The rapeseed and mustard grown in Bangladesh comprise three species viz. B. campestris, B. juncea, and the newly introduced B. napus. These crops have the largest zone and production among the oil crops grown in Bangladesh. Genetic diversity is vital to develop cultivars with improved yields, wider adaptation, desirable qualities, and pest and disease resistance. Inclusion of other diverse parents (within a limit) in hybridization is supposed to raise the chance of obtaining supreme heterosis and give a wide spectrum of variability in segregating groups. Variability and genetic diversity are the ultimate law of plant breeding which is a major tool being used in parent selection for effective hybridization program [1]. However, its partial geographic choice and intensive breeding has run to a moderately narrow genetic basis in present breeding material. The gene pool of best oilseed rape breeding material has been further worn by an emphasis on explicit oil and seed quality characters. As a consequence, genetic inconsistency in this vital crop is delimited with regard to many types of value for breeding purposes. Approximations of genetic diversity in a crop species can contribution in the valuation of germplasm collections as potential gene pools to improve the concert of cultivars. Genotyping accessions and assessing the level of genetic diversity inside a germplasm group can be of use to plant breeders in a number of ways. With this aim, an attempt was made in the present study to analyse genetic diversity among 22 advanced genotypes of B. napus.

\section{Materials and Methods}

Twenty two progressive genotypes of B. napus were grown in randomized complete block design with three replications. The advanced lines of Brassica napus L. for the trial were collected from the Department of Genetics and Plant Breeding, Sher-e-Bangla Agricultural University (SAU) and three released varieties collected from Bangladesh Agricultural Research Institute (BARI) as presented in Table 1. The plot size was $3 \mathrm{~m}$ length with two rows. Row to row and plant to plant distances were $25 \mathrm{~cm}$ and $15 \mathrm{~cm}$, respectively. Seeds were sown in lines in the trial plots. Observations were recorded on 10 randomly chosen plants from each plot. Data were collected on Days to 1 st Flowering, Days to $50 \%$ Flowering, Days to $80 \%$ flowering, Days to maturity, Plant height (cm), Number of primary branches per plant, Number of secondary branches per plant, Siliqua/Plant, Siliqua/length (cm), Number of seeds per siliqua, 1000 seeds weight $(\mathrm{g})$ and Seed yield per plant $(\mathrm{g})$. Multivariate analysis viz., Principal Component Analysis (PCA), Principal Coordinate Analysis (PCO), Cluster Analysis (CLU) was done by using GENSTAT 5 Release 4.1 (PC/Windos NT) software program [2].

Table-1. List of the 40 Brassica napus L. genotypes used in the experiment with their sources

\begin{tabular}{l|l|l|l|l|l}
\hline Genotype No. & Name/Acc No. & Source & Genotype No. & Name/Acc No. & Source \\
\hline G1. & Nap-0717-2 & BARI & G21. & Nap-10014 & BARI \\
\hline G2. & Nap-0733-1 & BARI & G22. & Nap-10012 & BARI \\
\hline G3. & Nap-0762 & BARI & G23. & Nap-0130 & BARI \\
\hline G4. & Nap-08-4 & BARI & G24. & Nap-2012 & BARI \\
\hline G5. & Nap-0837 & BARI & G25. & Nap-2013 & BARI \\
\hline G6. & Nap-0865 & BARI & G26. & Nap-2022 & BARI \\
\hline G7. & Bap-0869 & G27. & Nap-9906 & BARI \\
\hline G8. & Bap-0876 & BARI & G28. & Nap-9908 & BARI \\
\hline G10. & BARI & G29. & Nap-248 & BARI \\
\hline G11. & Bap-0885 & G30. & Nap-2001 & BARI \\
\hline G12. & BAR-205 & BARI & G31. & Nap-9904 & BARI \\
\hline G13. & BARI-13 & BARI & G32. & Nap-9905 & BARI \\
\hline G14. & Nap-10007 & BARI & G33. & Nap-2057 & BARI \\
\hline G15. & Nap-10009 & BARI & G34. & Nap-2037 & BARI \\
\hline G16. & Nap-10015 & BARI & G35. & Nap-206 & BARI \\
\hline G17. & Nap-10017 & BARI & G36. & Nap-2066 & BARI \\
\hline G18. & Nap-10019 & BARI & G37. & Nap-179 & BARI \\
\hline G19. & Nap-10020 & BARI & G38. & Nap-108 & BARI \\
\hline G20. & Nap-1005 & BARI & G39. & BARI \\
\hline
\end{tabular}

\section{Result and Discussion}

\subsection{Diversity of the Brassica Napus L Lines}

Genetic diversity analysis involves several steps, i.e., estimation of distance between the varieties, clustering and analysis of inter-cluster distance. Therefore, more than one multivariate technique was required to represent the results more clearly and it was obvious from the results of many researchers Brassica napus L multivariate techniques were used. 


\subsection{Construction of Scatter Diagram}

Based on the values of principal component scores 2 and 1 obtained from the main component analysis, a two dimensional scatter figure $\left(\mathrm{Z}_{1}-\mathrm{Z}_{2}\right)$ using component mark 1 as $\mathrm{X}$-axis and component score 2 as $\mathrm{Y}$-axis was constructed, which has been presented in Figure 1. The position of the genotypes in the scatter graph was apparently distributed into five groups, which designated that there existed considerable diversity among the genotypes.

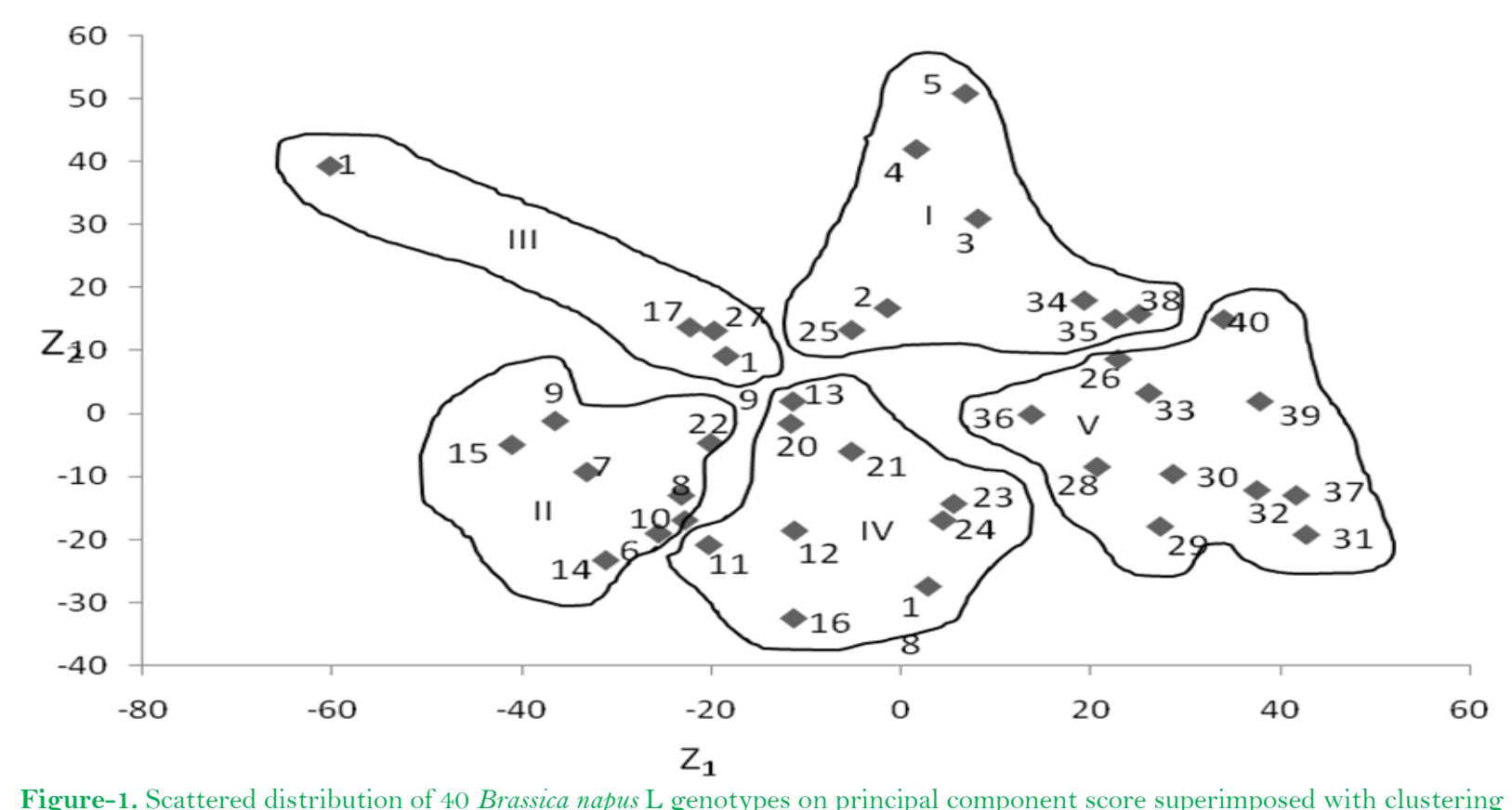

\subsection{Principal Component Analysis (PCA)}

$\mathrm{D}^{2}$ analysis through non-hierarchical grouping has taken care of simultaneous disparity in all the characters under study. The scattering of genotypes in different clusters of the $\mathrm{D}^{2}$ analysis has tailed similar trend of the $Z_{1}$ and $\mathrm{Z}_{2}$ vectors of the main component analysis. The $\mathrm{D}^{2}$ and principal component analysis were found to be another method in giving the information about the support of characters towards divergence of rapeseed and mustard.

Generally genetic diversity is related with geographical diversity but the former is not essentially directly related with geographical circulation. The genotype within the same cluster while formed specific clusters but were collected or originated from different places which indicated the topographical distribution and genetic separation did not follow the same trend. In the current study pattern of clustering revealed that genotypes originating from the similar country did not form a single cluster. The genotypes originating from dissimilar countries were grouped in the similar cluster (Table 3). This indicates that topographical diversity was not related to genetic diversity, which might be due to nonstop exchange of genetic materials amongst the countries of the world.

Most important components were computed from the correlation matrix and genotype scores obtained from first apparatus and ensuing mechanism with dormant roots greater than the unity donation of the different morphological characters towards divergence were discussed from the dormant vectors of the first two most important component. The major Component Analysis yielded Eigen values of each major Component axes with the first axes entirely bookkeeping for the variation among the genotypes, while three of these with Eigen values above unity accounted for $42.77 \%$. The first two major axes accounted for $57.07 \%$ of the total variation among the 12 characters recounting 40 lines (Table 2). Based on major Component axes I and II, a two dimensional chart $\left(Z_{1}-\right.$ $Z_{2}$ ) of the cultivars are offered in (Figure 1). The scattered diagram discovered that apparently there were mainly five clusters.

In vector $\mathrm{I}\left(\mathrm{Z}_{\mathrm{I}}\right)$ obtained from $\mathrm{PCA}$, the significant characters dependable for genetic divergence in the axis of discrimination were days to $50 \%$ flowering (5.137). Plant height (0.756), secondary branches/plant (0.578) and siliqua/plant (0.429). In vector II $\left(Z_{2}\right)$, the second axis of discrimination, primary branches per plant (0.711), Number of seeds per siliqua (0.031), Siliqua per plant (0.429) and thousand seeds weight were imperative because all these characters had optimistic signs. On the other hand days to maturity, primary branches per plant, siliqua length, seeds per siliqua, thousand seeds weight and seed yield per plant in the first axis of delineation and days to maturity, siliqua length and seed yield per plant in the second axis of delineation had a minor role in the genetic divergence because they had productive signs. Leaf length and siliqua per plant in both the vectors had constructive signs, which indicated they were the significant component characters having higher involvement to the genetic divergence among the materials calculated. It was distincted that three methods gave similar results. But factorial makes a distinction and Mahalanobis's $\mathrm{D}^{2}$ distance methods mandatory collecting data plant by plant, while the PCA method obligatory taking data by plots. 
Table-2. Eigen values and percentage of variation in respect of twelve characters in Brassica napus L

\begin{tabular}{l|l|l|l}
\hline Principal component axis & Eigen values & \% of total variation accounted for & Cumulative percent \\
\hline I & 5.132 & 42.77 & 42.77 \\
\hline II & 1.716 & 14.3 & 57.07 \\
\hline III & 1.452 & 12.1 & 69.17 \\
\hline IV & 0.965 & 8.04 & 77.21 \\
\hline V & 0.756 & 6.3 & 83.51 \\
\hline VI & 0.711 & 4.93 & 89.44 \\
\hline VII & 0.578 & 3.58 & 94.25 \\
\hline VIII & 0.429 & 1.9 & 97.83 \\
\hline IX & 0.228 & 0.26 & 99.73 \\
\hline X & 0.031 & 0 & 99.99 \\
\hline XII & 0 & 0 & 99.99 \\
\hline
\end{tabular}

Among five clusters, cluster I was unruffled of eight lines: 2,3,4,5,25,34,35 and 38. From the clustering mean value (Table 3), it was pragmatic that cluster I fashioned the highest mean for days to first flowering (58.54 days), days to $50 \%$ flowering (60.75 days), days to $80 \%$ flowering (63.50 days), Days to maturity (105.14 days), Plant height $(107.99 \mathrm{~cm})$, Number of primary branch per plant (3.49), Number of secondary branch per plant (3.49), Siliqua per plant (146.19), Siliqua per length $(7.49 \mathrm{~cm})$, seed per Siliqua (22.99), thousand seed weight (3.39 gm) and seed weight per plant (11.72 gm) (Table 3). Cluster II was composed of eight lines; 6,7,8,9,10,14,15 and 22. These genotypes formed the highest mean for seed weight per plant $(12.35 \mathrm{gm})$. Cluster III was constituted of four lines; 1,17,19, and 27. The genotypes of this cluster formed the highest mean for Siliqua per length $(7.62 \mathrm{~cm})$, seed per Siliqua (24.27) and lowest value for Number of secondary branch per plant (3.93) and Siliqua per plant (130.25). Cluster IV constituted of nine genotypes, lines; 1,12,13,16,18,20,21,23 and 24. The line produced the highest mean for Siliqua per length $(7.62 \mathrm{~cm})$, yield per plant $(11.89 \mathrm{gm})$ and lowest value for Plant height $(92.55 \mathrm{~cm})$. Cluster V constituted of eleven genotypes; line 26,28,29,30,31,32,33,36,37,39 and 40. The genotypes of this cluster produced the highest mean values for Plant height $(118.63 \mathrm{~cm})$, Number of secondary branch per plant $(4.82)$, Siliqua per plant (181.39). Jagadev, et al. [3] showed utmost genetic distance in between cluster III and IV suggesting wide diversity in rapeseed and mustard.

Table-3. Distribution of 40 Brassica napusL genotypes in five different clusters

\begin{tabular}{l|l|l|l}
\hline Cluster & Total no. of line & Genotype Number & Genotype Designation \\
\hline I & 8 & $2,3,4,5,25,34,35,38$ & $\begin{array}{l}\text { Nap-0733-1, Nap-0762, Nap-08-4, Nap-0837, Nap- } \\
\text { 2013, Nap-2057, Nap-2037, Nap-179 }\end{array}$ \\
\hline II & 8 & $6,7,8,9,10,14,15,22$ & $\begin{array}{l}\text { Nap-0865, Nap-0869, Nap-0876, Nap-0885, Nap- } \\
205, \text { Nap-10009, Nap-10015, Nap-10012 }\end{array}$ \\
\hline III & 4 & $1,17,19,27$ & Nap-0717-2, Nap-10019, Nap-1005, Nap-9906 \\
\hline IV & 9 & $11,12,13,16,18,20,21,23,24$ & $\begin{array}{l}\text { BARI-8, BARI-13, Nap-10007,Nap-10017, Nap- } \\
10020, \text { Nap-1007, Nap-10014, Nap-0130, Nap-2012 }\end{array}$ \\
\hline V & 11 & $26,28,29,30,31,32,33,36,37,39,40$ & $\begin{array}{l}\text { Nap-2022, Nap-9908, Nap-248, Nap-2001, Nap- } \\
9901, \text { Nap-9904, Nap-9905, Nap-206, Nap-2066, } \\
\text { Nap-94006, Nap-108 }\end{array}$ \\
\hline
\end{tabular}

Table-4. Cluster means for twelve characters of Brassica napus L

\begin{tabular}{|c|c|c|c|c|c|}
\hline \multirow{2}{*}{ Characters } & \multicolumn{5}{|l|}{ Cluster } \\
\hline & I & II & III & IV & $\mathbf{V}$ \\
\hline Days to 1 st Flowering & 58.54 & 32.58 & 39.58 & 42.89 & 57.82 \\
\hline Days to $50 \%$ Flowering & 60.75 & 34.58 & 41.58 & 44.89 & 59.82 \\
\hline Days to $80 \%$ flowering & 63.50 & 37.25 & 44.25 & 47.56 & 62.55 \\
\hline Days to maturity & 105.14 & 85.48 & 88.38 & 90.81 & 102.85 \\
\hline Plant height $(\mathrm{cm})$ & 107.99 & 90.39 & 98.69 & 92.55 & 118.63 \\
\hline No. of primary branch/plant & 3.49 & 2.97 & 3.12 & 3.25 & 3.45 \\
\hline No. of secondary branch/plant & 4.20 & 3.96 & 3.93 & 4.16 & 4.82 \\
\hline Siliqua/Plant & 146.19 & 157.48 & 130.25 & 173.14 & 181.39 \\
\hline Siliqua/length $(\mathrm{cm})$ & 7.49 & 7.43 & 7.62 & 7.62 & 7.49 \\
\hline Seed/Siliqua & 22.99 & 21.76 & 24.27 & 22.62 & 22.99 \\
\hline Seed wt (1000) gm & 3.39 & 3.33 & 3.46 & 3.63 & 3.53 \\
\hline wt of plant seed (gm) & 11.72 & 12.35 & 11.46 & 11.89 & 11.68 \\
\hline
\end{tabular}

\subsection{Canonical Variety Analysis}

Canonical Variety Analysis was performed to calculate the inter-cluster Mahalanobis's values. Statistical distances indicate the index of genetic diversity in the midst of the clusters. The average intra and inter-cluster distance $\left(\mathrm{D}^{2}\right)$ values were offered in Table 5. Consequences indicated that the highest inter-cluster distance was observed between II and V (8.145), followed by between I and II (7.767), III and V (7.434). The lowest inter-cluster distance was observed between the cluster II and IV (3.917) followed by I and V (3.958), II and III (5.308) suggesting a close relationship among these clusters (Figure 2 ). The inter-cluster distances were larger than the intra-cluster distances suggesting wider genetic diversity among the genotypes of dissimilar groups (Figure 2). Uddin [4] obtained superior inter-cluster distances in the multivariate analysis in mustard. Khan [5] reported alike results in raya. Subordinate intra-cluster distances in all the eight clusters indicated the genotypes within the same cluster were strongly allied.

Conversely, the utmost inter-cluster distance was recorded between cluster II and V (8.145) followed by between I and II (7.767), III and V (7.434). Genotypes from these clusters if implicated in hybridization might 
fabricate a wide range of segregating population, as genetic variation was very discrete among these groups. The inter-cluster divergence varied from 0.304 to 0.420 utmost being from cluster $\mathrm{V}$ which comprised of eleven cultivars of diverse origin, while the minimum distance was pragmatic in cluster III which comprised only four lines (Table 5). Alike results were obtained by Anand and Rawat [6] in brown mustard. Verma and Sachan [7] observed no parallelism between geographic and genetic diversity. Gupta, et al. [8] showed no correlation between geographic and genetic diversity. Mitra and Saini [9] reported no substantiation for any correlation between genetic divergence and geographic diversity. Chatterjee and Khare [10] studied a downbeat relationship between geographic and genetic diversity.

Consequences obtained from different multivariate techniques were superimposed in Figure 1 from which it might be accomplished that all the techniques gave more or less similar results and one technique supplemented and deep-rooted the results of another one. The clustering blueprint of the lines bare that varieties/lines originating from the same places did not form a single cluster because of direct selection pressure. It has been observed that geographic diversity is not always allied to genetic diversity and therefore, it is not ample as an index of genetic diversity. Kumar, et al. [11] premeditated that genetic drift and selection in different environment could cause greater diversity than geographic distance.

Additionally, there is a complimentary replace of seed material among different region as a upshot, the characters assemblage that might be associated with fastidious region in nature loose their individuality under human obstruction and however, in some cases effect of geographic origin predisposed clustering that is why geographic allocation was not the sole criterion of genetic diversity. The free cluster of the lines suggested confidence upon directional selection pressure practical for realizing maximum yield in different regions; the nicely evolved homeostatic campaign would favour fidelity of the associated characters. This would suggest that it was not necessary to choose diverse parents for diverse geographic regions for hybridization.

\begin{tabular}{l|l|l|l|l|l}
\multicolumn{5}{c}{ Table-5. Average intra and inter-cluster distances $\left(\mathrm{D}^{2}\right)$ for 40 Brassica napusL lines } \\
\hline Cluster & I & II & III & IV & V \\
\hline I & $\mathbf{0 . 4 2 0}$ & & & & \\
\hline II & 7.767 & $\mathbf{0 . 3 8 4}$ & & & \\
\hline III & 5.331 & 5.308 & $\mathbf{0 . 4 1 4}$ & & \\
\hline IV & 6.563 & 3.917 & 5.728 & $\mathbf{0 . 3 9 8}$ & \\
\hline V & 3.958 & 8.145 & 7.434 & 6.116 & $\mathbf{0 . 3 0 4}$ \\
\hline
\end{tabular}

Note: *Bold figures denotes intra-cluster distance.

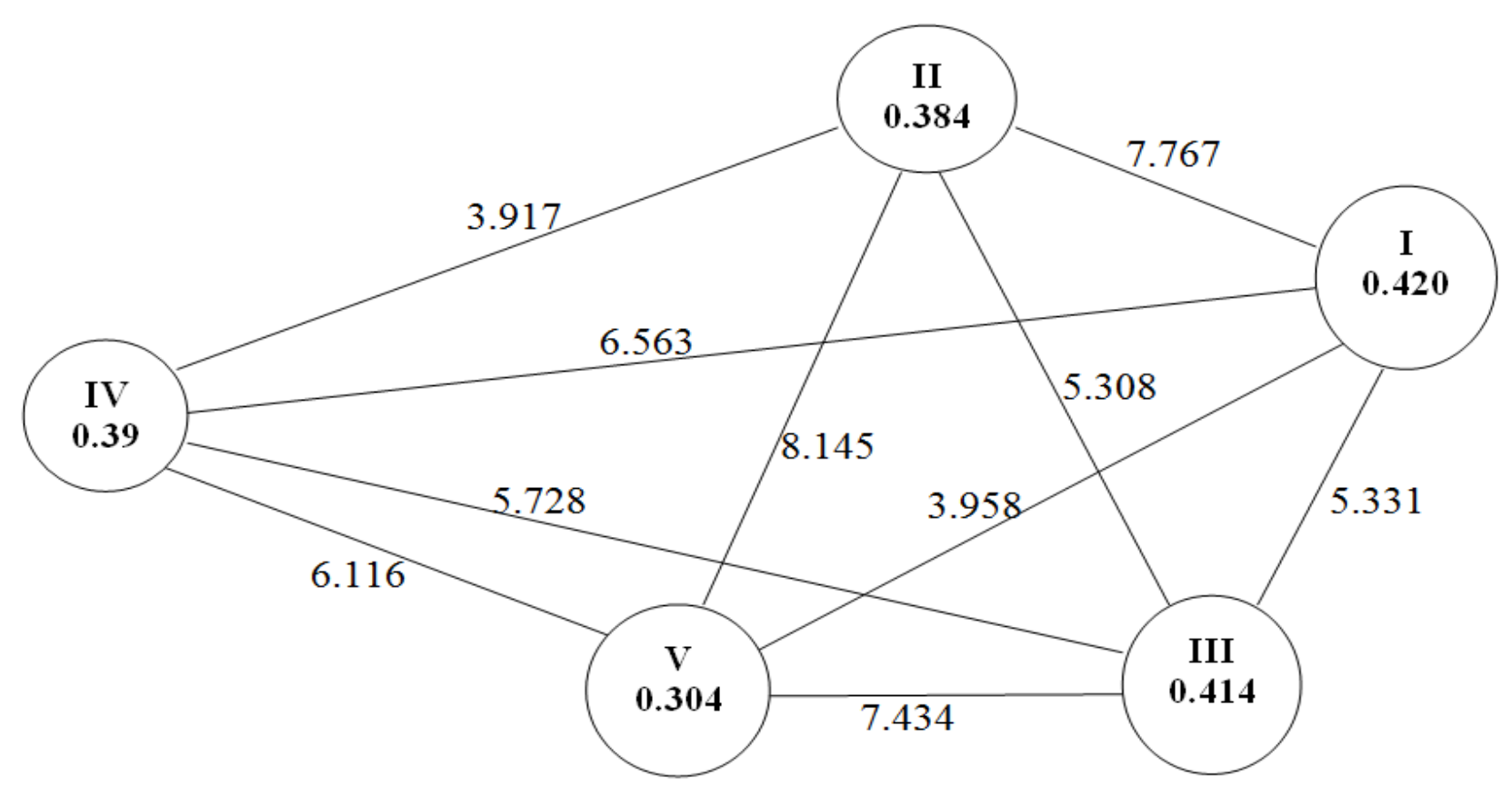

Figure-2. Diagram showing inter-cluster (outside the circle) and intra-cluster (inside the circle) distances of 40 genotypes of Brassica napus L

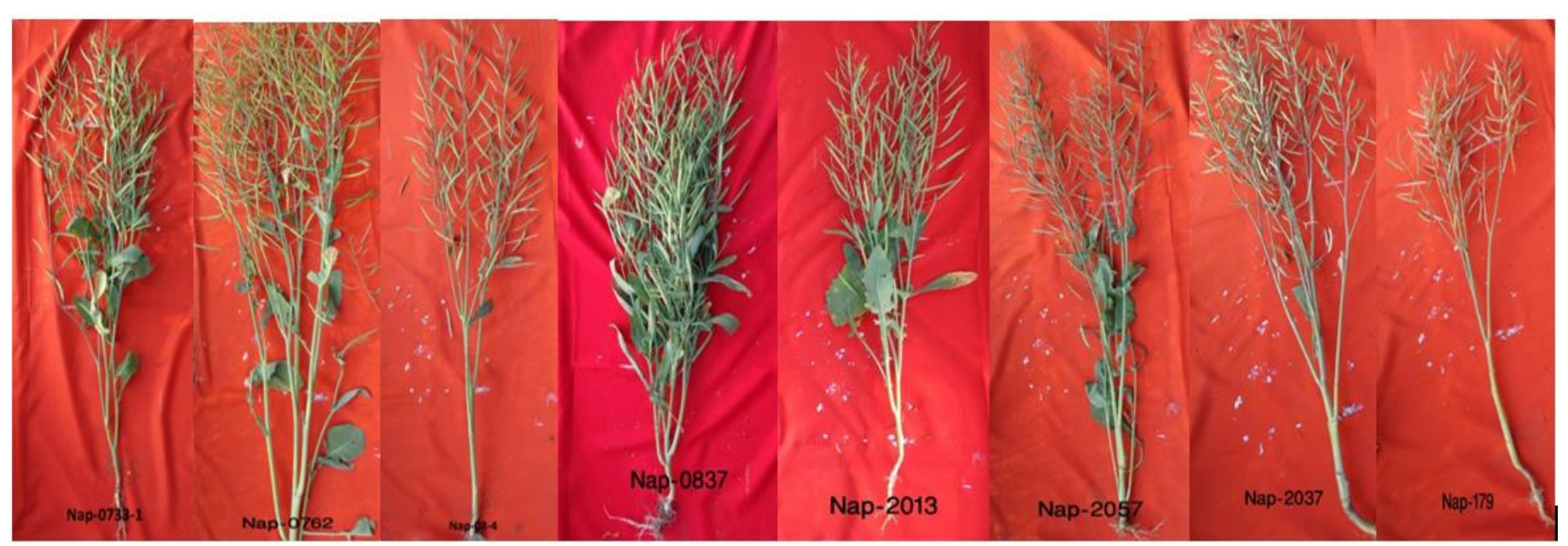

Plate-1. Photograph showing seed type of the different genotypes of cluster I 


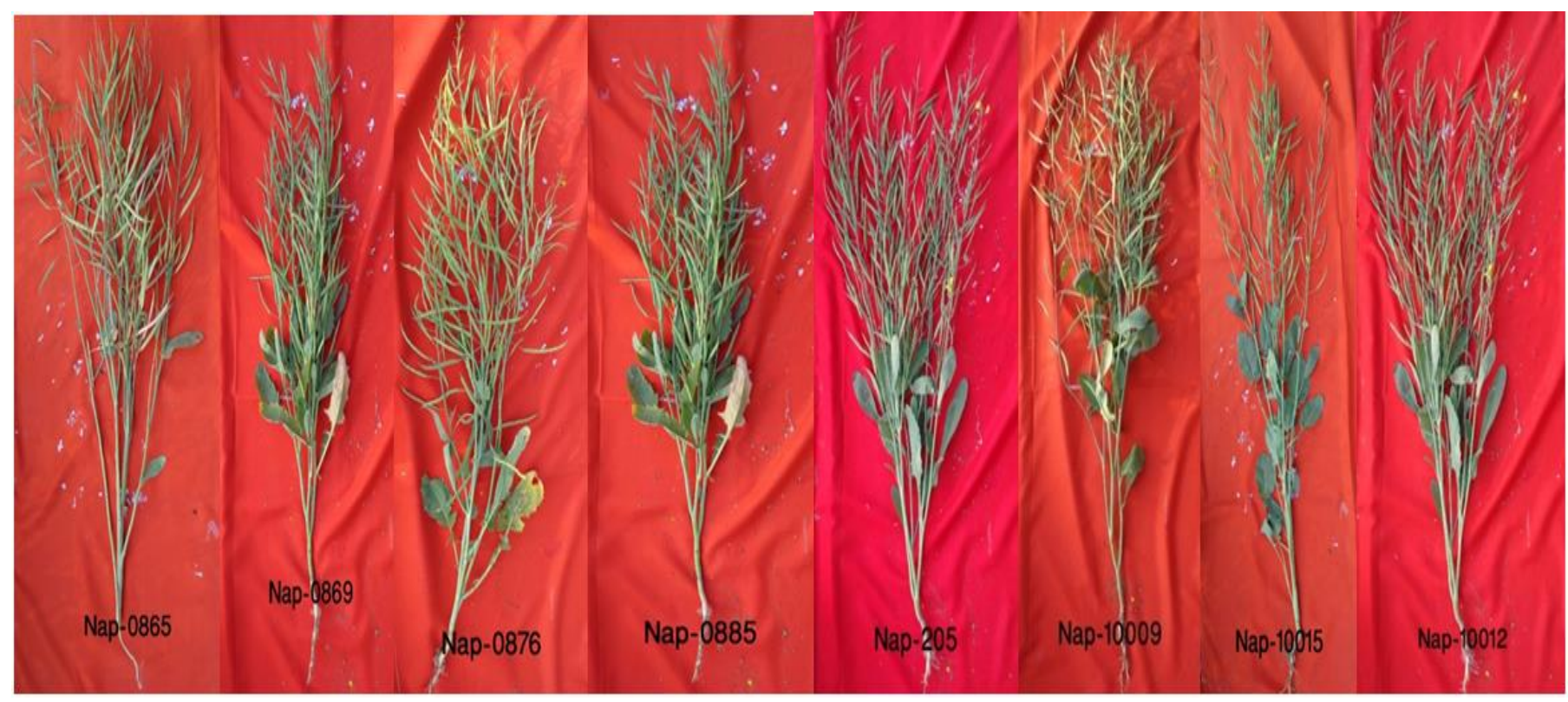

Plate-2. Photograph showing plant type of the different genotypes of cluster II
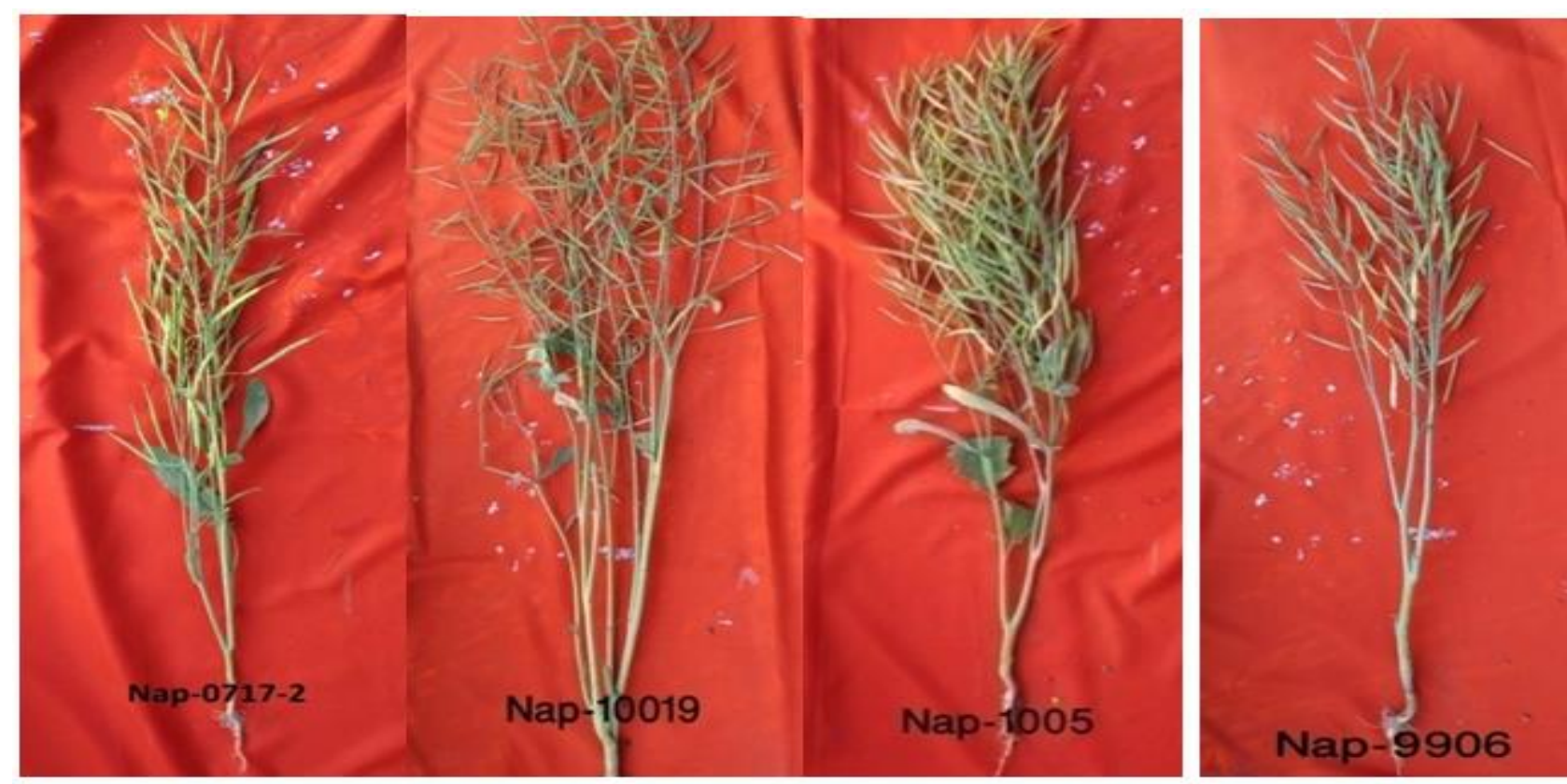

Plate-3. Photograph showing plant type of the different genotypes of cluster III

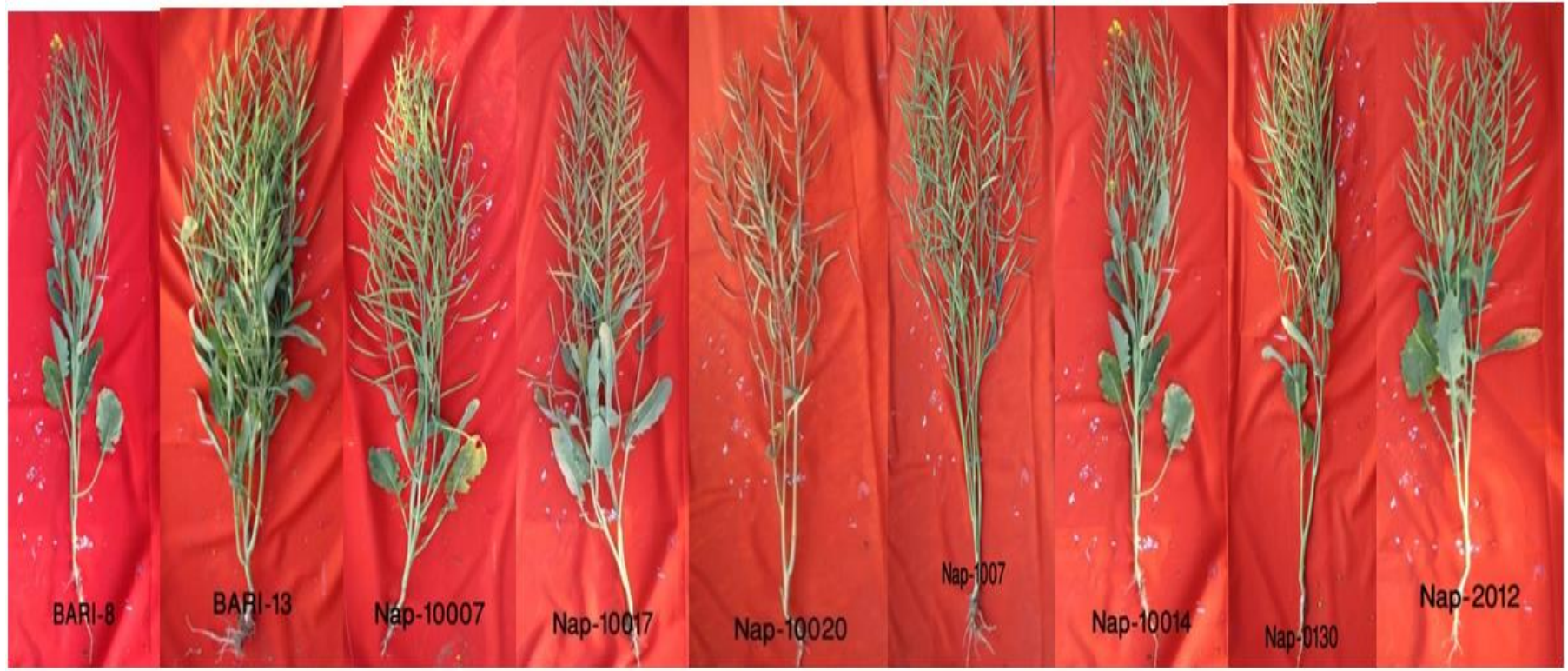

Plate-4. Photograph showing plant type of the genotype of cluster IV 


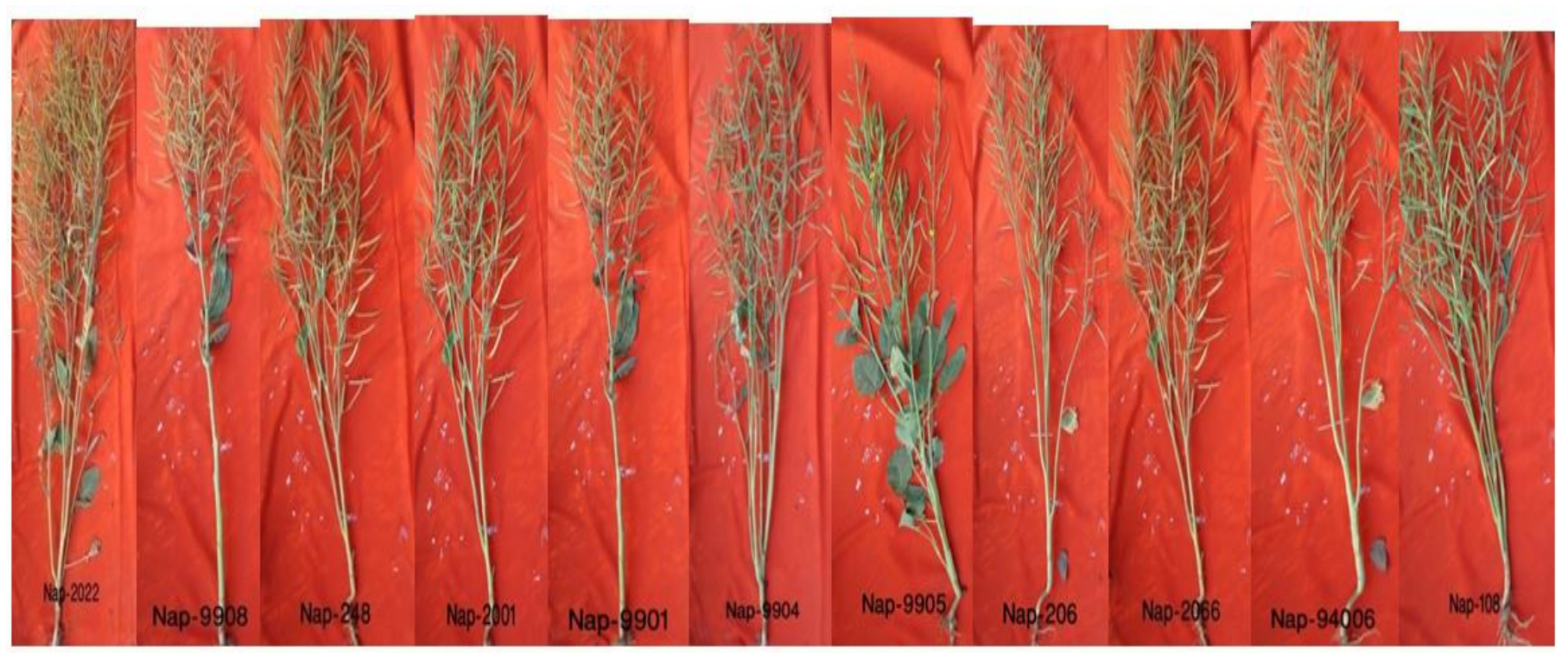

Plate-5. Photograph showing plant type of the genotype of cluster V

\subsection{Non-Hierarchical Clustering}

The multiplication from co-variance matrix gave non-hierarchical clustering among 40 genotypes. By application of non- hierarchical clustering using covariance matrix, the 40 Brassica napus L genotypes were grouped into five different clusters. These results confirmed the clustering pattern of the lines according to the Principal Component Analysis. So, the results obtained through PCA were confirmed by non-hierarchical clustering. Compositions of unlike clusters with their corresponding lines integrated in cluster were presented in Table 3. Cluster V had utmost eleven lines followed by cluster I, II, IV, and III, which had eight, eight, nine and four genotype correspondingly. Cluster IV self-possessed of five lines; 1,17,19,27. Verma and Sachan [7] reported 12 clusters; Gupta, et al. [8] five clusters; Khan [5] seven clusters and Srivastava and Singh [12] six clusters in rapeseed and mustard. These results deep-rooted the clustering pattern of the genotypes according to the major component analysis.

From the clustering mean value (Table 4), pragmatic that cluster I produced the highest mean for days to first flowering (58.54 days), days to $50 \%$ flowering (60.75 days), days to $80 \%$ flowering (63.50 days), Days to maturity (105.14 days), Plant height $(107.99 \mathrm{~cm})$, Number of primary branch per plant (3.49), Number of secondary branch per plant (3.49), Siliqua per plant (146.19), Siliqua per length $(7.49 \mathrm{~cm})$, seed per Siliqua (22.99), thousand seed weight (3.39 gm) and seed weight per plant (11.72 gm). Photograph showing seed, Siliqua and plant of the different genotypes of this cluster has been offered in Plate 1.

Cluster II was self-possessed of eight lines; 6,7,8,9,10,14,15 and 22. These genotypes fashioned the highest mean for seed weight per plant $(12.35 \mathrm{gm})$. Photograph showing eed, Siliqua and plant of the different genotypes of this cluster has been presented in Plate 2. Cluster III was constituted of four lines; 1,17,19, and 27. The genotypes of this cluster fashioned the highest mean for Siliqua per length $(7.62 \mathrm{~cm})$, seed per Siliqua $(24.27)$ and lowest value for Number of secondary branch per plant (3.93) and Siliqua per plant (130.25). Photograph screening seed, Siliqua and plant of the different genotypes of this cluster has been existing in Plate 3. Cluster IV constituted of nine genotypes, lines; 11,12,13,16,18,20,21,23 and 24. The line formed the highest mean for Siliqua per length $(7.62 \mathrm{~cm})$, yield per plant $(11.89 \mathrm{gm})$ and lowest value for Plant height $(92.55 \mathrm{~cm})$. Photograph screening seed, Siliqua and plant of the different genotypes of this cluster has been offered in Plate 4. Cluster V constituted of eleven genotypes; lines; 26,28,29,30,31,32,33,36,37,39 and 40. The genotypes of this cluster formed the highest mean values for Plant height $(118.63 \mathrm{~cm})$, Number of secondary branch per plant (4.82), Siliqua per plant (181.39). Photograph viewing seed, Siliqua and plant of the different genotypes of this cluster has been presented in Plate 5. From the class mean value it was observed that all the cluster mean values were more or less alike. The utmost range of variability was pragmatic for yield $(11.46 \mathrm{~g}$ to $12.35 \mathrm{~g})$ among all the characters in five clusters. Cluster II integrated mainly early flowering and early maturing genotypes with high yield. To develop high yielding varieties/lines, genotypes of this group could be used in hybridization program.

\subsection{Selection of Genotypes for Future Hybridization}

Genotypically far-away parents are competent to fabricate higher heterosis. Consequences of the present studies indicated noteworthy variation among the genotypes for all the characters studied. Number of Siliqua per plant, Siliqua length and seed weight per plant contributed maximum towards yield perfection. Forty Brassica napus L genotypes formed five different clusters. PCA and Cluster analysis gave alike results. By and large, diversity was influenced by the morphological characters, but not by the distribution of the genotypes, which indicated the consequence of consumer preference and growers aptness. Considering diversity pattern and other agronomic performance lines Nap-0837, Nap-0733-1, Nap-2066, Nap-9901, Nap-108 and BARI-8 could be measured suitable genotypes for well-organized hybridization in future. Concerning of such diverse lines in crossing curriculum could produce enviable segregants. So, more or less divergent genotypes are suggested to use as parents in future hybridization program.

\section{Conclusion}

Assortment of genetically diverse parents is the most important assignment for any plant breeding actions. For that reason, taking into consideration the extent of genetic distance, contribution of character towards divergence, magnitude of cluster mean and agronomic performance the following genotypes were promising: in view of diversity pattern and other agronomic performance lines Nap-0837, Nap-0733-1, Nap-2066, Nap-9901, Nap-108 and BARI-8 might be recommended for future hybridization program. 


\section{References}

[1] G. Bhatt, "Comparison of various methods of selecting parents for hybridization in common bread wheat (Triticum Aestivum L.)," Australian Journal of Agricultural Research, vol. 24, pp. 457-464, 1973. Available at: https://doi.org/10.1071/ar9730457.

P. Digby, M. Galway, and P. Lane, GENSTAT. A second course. Oxford: Oxford Science Publications, 1989.

P. Jagadev, K. Samal, and D. Lenka, "Genetic divergence in rape mustard," The Indian Journal of Genetics and Plant Breeding, vol. 51 , pp. 465-467, 1991.

M. J. Uddin, "Genetic divergence in mustard," Bangladesh Journal of Plant Breeding and Genetics, vol. 7, pp. 23-27, 1994.

M. N. Khan, "Multivariate analysis in Raya," Applied Biological Research, vol. 2, pp. 169-171, 2000.

I. Anand and D. Rawat, "Genetic diversity, combining ability and heterosis in brown mustard," The Indian Journal of Genetics and Plant Breeding, vol. 44, pp. 226-234, 1984.

[7] S. Verma and J. Sachan, "Genetic divergence in Indian mustard (Brassica Juncea (L.) Czern \& Coss.)," Crop Research (Hisar), vol. 19, pp. 271-276, 2000.

[8] M. Gupta, K. S. Labana, and S. S. Badwal, "Correlation and path co $\neg$ efficient of metric traits contributing towards oil yield in Indian mustard," presented at the International Rapeseed Congress, Pozan, Poland, 107(En), 1987.

[9] J. Mitra and H. Saini, "Genetic divergence for yield and its components in toria (Brassica Campestris var. Toria)," International Journal of Tropical Agriculture, vol. 16, pp. 243-246, 1998.

[10] A. Chatterjee and D. Khare, "Multivariate analysis in Niger," Research and Development Reporter, vol. 8, pp. 111-114, 1991.

[11] C. H. M. V. Kumar, V. Arunachalam, and P. S. K. Rao, "Ideotype and relationship between morpho-physiological characters and yield in Indian mustard (B. Juncea)," Indian Journal of Agricultural Science, vol. 66, pp. 14-17, 1996.

[12] M. K. Srivastava and R. P. Singh, "Genetic divergence in Indian mustard," Crop Research Hisar, vol. 20, pp. 555-557, 2000. 